\title{
Herpetological Journal \\ https://doi.org/10.33256/31.1.4654 \\ Habitat use and age structure of the Fer-de-Lance (Bothrops asper, Viperidae) in Braulio Carrillo National Park, Costa Rica
}

\author{
Daniel G. Ramírez-Arce ${ }^{1}$, Alejandro Zúñiga-Ortiz ${ }^{1,2}$ \& Dennis K. Wasko³ \\ ${ }^{1}$ Universidad Nacional de Costa Rica, Heredia 40101, Costa Rica \\ ${ }^{2}$ Universidad Técnica Nacional, Puntarenas 60101, Costa Rica \\ ${ }^{3}$ Hillyer College, University of Hartford, West Hartford, Connecticut 06117, USA
}

\begin{abstract}
The Fer-de-lance or terciopelo (Bothrops asper) inhabits a wide range of environmental conditions and habitats across Central America. While much information on the species is based on anecdotal observations and museum specimens, data collected under natural conditions are more limited. To better document its natural history, this study sought to determine the habitat use and age structure of B. asper in the Quebrada Gonzalez sector of Braulio Carrillo National Park, Costa Rica. Snake surveys were conducted from January 2015 to August 2017 and used to evaluate the population age-class distribution and sex ratio. To evaluate macrohabitat use, surveys were conducted in four habitat types (mature forest, late succession, early succession, and human infrastructure). Microhabitat use was determined by recording several structural variables at each snake location and at random sites. Amphibians were sampled in each habitat type to evaluate the available prey base. Fifty-five individuals were captured, mostly females and juveniles, with five recaptures. Snakes were encountered in all habitat types but most often in early succession forests, which have dense vegetation cover and high prey availability. Snakes selected areas with heavy understory cover when resting, and more exposed sites, often closer to bodies of water, when ambushing prey or moving. Human-disturbed sites were used least. Although snake encounters did tend to correlate with higher amphibian abundance, other factors such as mammalian prey abundance could also influence snake distribution.
\end{abstract}

Keywords: occupancy, population ecology, habitat selection, behaviour, predator-prey relationship

\section{INTRODUCTION}

T he venomous snake genus Bothrops (Serpentes: Viperidae) is well-known for its widespread geographic distribution across Latin America, occurrence in a wide variety of habitats, diversity of species, and for being the primary cause of snakebites throughout the region (Oliveira, 2001; Valdujo et al., 2002; Nogueira et al., 2003; Hartmann et al., 2005). In addition to natural habitats, some species such as $B$. asper, $B$. atrox, and $B$. jararaca frequently display a willingness to utilise areas modified and used by humans (e.g. plantations, rural villages), resulting in extensive interactions with humans and therefore correspondingly a high number of snakebites (Martins et al., 2001; Oliveira, 2001). This is particularly true for $B$. asper, popularly known as the "terciopelo" or "barba amarilla" in its local range, and "Fer-de-Lance" or "lancehead" in the English-speaking world. This snake has strongly cryptic colouration, potent venom, and often-high local abundance in various macroand microhabitats (including primary and secondary forests, swamps, pastures, agricultural plantations, and human settlements) across a variety of vegetation types (Bolaños, 1972; Janzen, 1980; Cisneros-Heredia \& Touzet, 2004; Sasa et al., 2009). Consequently, it is also the species responsible for the majority of snakebites and snakebite fatalities in Central and northern South America (Otero-Patiño, 2009).

Understanding $B$. asper's ecology and behaviour is an essential component of managing snakebite risk within its range. However, while a good deal of research has focused on the species' toxicology, reproduction, and systematics, relatively little has addressed its natural history or behaviour (Sasa et al., 2009). The majority of available natural history information was collected at La Selva Biological Station in Costa Rica (Wasko \& Sasa, 2009; Wasko \& Sasa, 2010; Wasko \& Sasa, 2012), to date the only comprehensive studies to address the behavioural ecology of $B$. asper under natural conditions. Although these studies were carried out at a single lowland-rainforest site at a somewhat fragmented and highly-visited field, their results have been used to propose snakebite-management measures throughout a wide region of Costa Rica (Hansson et al., 2013). Further 


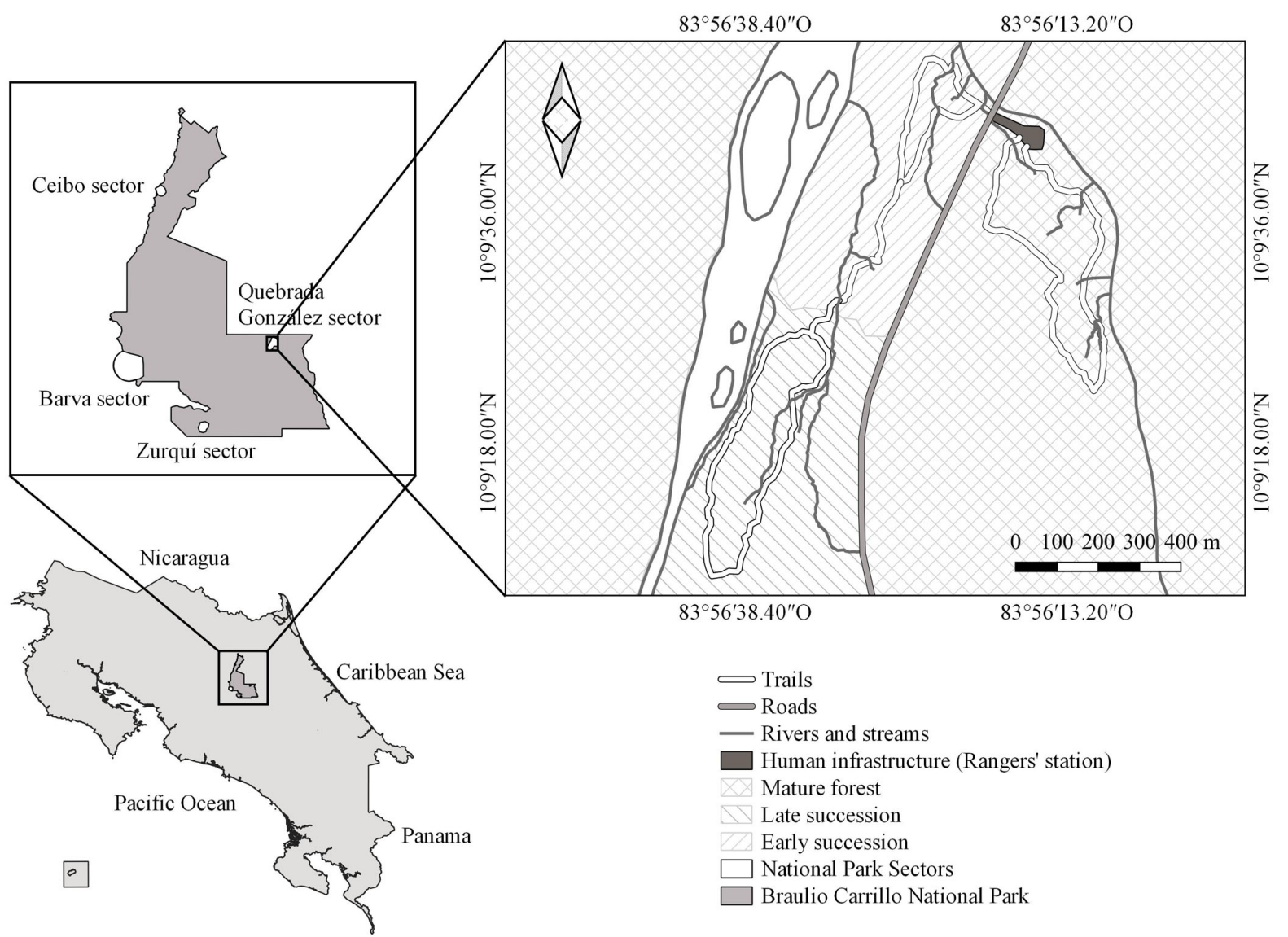

Figure 1. Map of Quebrada González sector of Braulio Carrillo National Park, Costa Rica, showing the location of habitat types, trails, ranger station, roads, rivers and streams. Boundaries between habitat types are approximate and show some transition. River and road data taken from ATLAS 2014 of the Instituto Tecnológico de Costa Rica (ITCR), Cartago, Costa Rica.

study in other natural and rural areas would be useful to further generalise our understanding of B. asper's ecology and to manage its snakebite risk (Brito, 2003; Pearson et al., 2005; Morrison et al., 2006).

We conducted an ecological survey of $B$. asper in the Quebrada González sector of Braulio Carrillo National Park in Costa Rica, an area that is contiguous with La Selva Biological Station but differs in size, elevational gradient, habitat diversity, degree of fragmentation, and rate of visitation by humans. No quantitative data on the ecology of $B$. asper exist for the site, but it is reported as common (Ramírez-Arce et al., 2019). Our specific goals were to; 1 ) determine the age-class distribution and sex ratio for the $B$. asper population, 2) evaluate macrohabitat and microhabitat use, and 3 ) assess the relationship between prey availability and $B$. asper abundance.

\section{METHODS}

\section{Study area}

Braulio Carrillo National Park is a large $(47,683$ ha) reserve located along the Cordillera Central mountain range of Costa Rica (Tenorio, 1993). Quebrada González sector is a 72 ha region on its eastern side, consisting largely of pluvial premontane forest transitioning to basal humid tropical forest, with an average elevation of $514.40 \pm 81.30 \mathrm{~m}$ and steep topography (Oviedo-Pérez \& Fournier-Gutierrez, 2008) (Fig. 1). The mean annual temperature is $24^{\circ} \mathrm{C}$ and mean annual precipitation is $6,375.50 \mathrm{~mm}$, with a distinct wet (May-December) and dry season (January-April; Guyer \& Donnelly, 1990). Vegetation cover includes mature forest, secondary forest, and a broad open area of riverbed with some grasslands (Lücking, 1999; Oviedo-Pérez \& FournierGutierrez, 2008; Vásquez-Acosta, 2009) (Fig. 1). Major river tributaries and smaller streams maintain a constant flow, providing abundant water resources throughout the year (Tenorio, 1993; Schelhas \& Sánchez-Azofeifa, 2006).

We classified the area into four distinct habitat types: Mature forest, Late succession, Early succession and Human infrastructure (Fig. 1). Mature forest, Late succession and Early succession comprised natural forested areas, while Human infrastructure a ranger station and surrounding disturbed areas (0.92 ha). Each habitat classification was determined using the literature (Lücking, 1999; Oviedo-Pérez \& Fournier-Gutierrez, 2008; Vásquez-Acosta, 2009) and by quantifying structural cover in natural areas. Ten vegetation sampling plots were randomly distributed along each natural area using QGIS 2.16.3 (QGIS, 2016). At each $10 \times 10 \mathrm{~m}$ plot we determined tree density, total basal area covered by trees, and diameter at breast height (DBH) of each tree with a diameter more than $5 \mathrm{~cm}$, while for trees with a diameter less than $5 \mathrm{~cm}$ we obtained only tree density (Table 1). Three unpaved trails with similar lengths (1.50-2.00 km) 
Table 1. Density of trees and basal area covered by trees for natural habitat types of Quebrada González sector, Braulio Carrillo National Park, Costa Rica. DBH = Diameter at breast height.

\begin{tabular}{|c|c|c|c|c|c|}
\hline \multirow{3}{*}{ Habitat type } & \multicolumn{5}{|c|}{ Tree diameter } \\
\hline & $\begin{array}{c}\text { DBH } \\
<5 \mathrm{~cm}\end{array}$ & \multicolumn{2}{|c|}{$\begin{array}{c}5 \mathrm{~cm} \leq \mathrm{DBH} \\
<10 \mathrm{~cm}\end{array}$} & \multicolumn{2}{|c|}{$\begin{array}{c}\text { DBH } \\
\geq 10 \mathrm{~cm} \\
\end{array}$} \\
\hline & No. /ha & No./ha & $\begin{array}{c}\text { Basal } \\
\text { area } \\
\left(\mathrm{m}^{2} / \mathrm{ha}\right)\end{array}$ & No./ha & $\begin{array}{c}\text { Basal } \\
\text { area } \\
\left(\mathrm{m}^{2} / \mathrm{ha}\right)\end{array}$ \\
\hline Early Succession & 1380 & 470 & 1.77 & 510 & 19.92 \\
\hline Late Succession & 1420 & 400 & 1.62 & 500 & 28.01 \\
\hline Mature Forest & 1150 & 290 & 1.23 & 730 & 33.77 \\
\hline
\end{tabular}

traverse the sector's natural areas, each predominantly through only one of these habitats. Trails were therefore used to access and assess natural habitats, while Human infrastructure was assessed by searching in its entire area.

\section{Snake surveys and age structure}

This study was conducted from January 2015 to August 2017. As tropical snakes may demonstrate seasonal variation in habitat use (Savage, 2002; Morrison et al., 2006), we surveyed both rainy and dry seasons each year. We conducted monthly field trips, each lasting three days, for a total of 28 field trips and 84 days of fieldwork. As $B$. asper shows a marked difference in behaviour and microhabitat use during day and night (Wasko \& Sasa, 2009; Wasko \& Sasa, 2010), we carried out 54 diurnal and 69 nocturnal surveys. The duration of each survey was 3 to 5 hours, carried out by two people, for a total survey effort of 350.80 person-hours during the day and 470.60 person-hours at night.

Snakes were located using standard visual-encounter surveys of about 3-5 hours each. For natural habitats, each survey was performed by searching either along their respective trails or along established $50 \times 2 \mathrm{~m}$ perpendicular rectangular transects that were $10 \mathrm{~m}$ from the actual trail. Transects were separated by 100 $\mathrm{m}$, resulting in 15 transects in Early succession, 20 in Late succession, and 16 in Mature forest. Trail length was 1,500 m for Early succession, 2,000 m for Late succession and 1,600 $\mathrm{m}$ for Mature forest, and we searched within $1.5 \mathrm{~m}$ of each side of the trail. For Human infrastructure, size and shape of the area didn't allow us to establish linear transects as in natural areas, so surveys were performed by searching throughout its area for 3-4 hours, with a search effort roughly equivalent to each natural habitat. The total survey effort in person-hours and total search area for each habitat type, is presented in Table 2.

Individual $B$. asper were manually captured using standard field tools and marked with PIT tags (Biomark ${ }^{\circledR}$, $8.40 \mathrm{~mm} 134.20 \mathrm{kHz}$ ISO FDX-B). Each snake was measured for total length (following the methods of Solórzano \& Cerdas, 1989) with a measuring tape and sex was determined by eversion of hemipenes (McDiarmid et al., 2012). Individuals were classified as juveniles
Table 2. Survey effort performed in each habitat type in Quebrada González sector, Braulio Carrillo National Park, Costa Rica.

\begin{tabular}{l|c|c|c}
\hline \multirow{2}{*}{ Habitat type } & \multicolumn{3}{|c}{ Total survey effort } \\
\cline { 2 - 4 } & $\begin{array}{c}\text { Search area } \\
\text { (ha) }\end{array}$ & \multicolumn{2}{|c}{ Person-hours } \\
\cline { 3 - 4 } & 0.64 & Day & Night \\
\hline Mature Forest & 91.00 & 122.40 \\
Late Succession & 0.80 & 103.80 & 117.60 \\
Early Succession & 0.60 & 92.00 & 140.60 \\
Human Infrastructure & 0.92 & 64.00 & 90.00 \\
\hline
\end{tabular}

if their total length was less than $99.50 \mathrm{~cm}$ (males) or $115 \mathrm{~cm}$ (females), and classified as adults otherwise, in accordance with the species size at sexual maturation (Solórzano \& Cerdas, 1989). From these data, we calculated the a) age-class distribution, b) overall sex ratio, and c) sex ratio within each age class. The specific point of capture was recorded with a GPS unit (Garmin $62 \mathrm{~s}$ ). Following data collection, snakes were released at the point of capture.

We also noted the snake's behaviour at the time it was found. Behaviours were classified as either resting (lying coiled or uncoiled with the head on the ground or on its own body), ambushing (lying coiled with the head raised and alert), or moving (if the snake was actually in motion horizontally or vertically).

\section{Habitat use and availability}

We assessed macrohabitat use by comparing the number of captures by habitat types (Mature forest, Late succession, Early succession and Human infrastructure). We assessed microhabitat use by recording a series of variables at each snake capture that have been documented as relevant to snakes (Blouin-Demers \& Weatherhead, 2001; Charland \& Gregory 1995; Wasko \& Sasa, 2010): Substrate type, canopy cover, ground cover, height, distance to nearest permanent water body, distance to nearest fallen log $\geq 10 \mathrm{~cm}$ diameter, and distance to nearest tree $\geq 25 \mathrm{~cm} \mathrm{DBH}$. Substrate type was the substrate on which the snake was located (e.g. soil, leaf litter, log, paved cement) and height the distance from the ground to the element of the habitat were the snake was encounter, such as if resting in a fallen log. Canopy cover was determined with a spherical crown densiometer and ground cover was calculated as the total percentage of the ground area covered by anything other than exposed soil/leaf litter, typically structural elements like low vegetation, following Charland \& Gregory (1995). Distances over $50 \mathrm{~m}$ were considered "not available" at that location based on typical movements of $B$. asper (Wasko \& Sasa, 2009).

In order to investigate habitat selection by snakes, we compared habitat use to availability, with nonrandom use considered active selection (BlouinDemers \& Weatherhead, 2001; Tozetti \& Martins, 2008). Macrohabitat availability was quantified as the proportion of each habitat type across the search area, determined using QGIS 2.16.3 (QGIS, 2016). For this purpose the "search area" was defined as the area 
searched for snakes (trails, transects, and the entire Human infrastructure, Table 1). For microhabitat, sixty random points distributed across all habitat types were generated at the study site using QGIS 2.16.3 (QGIS, 2016), they were treated like snake locations and the same microhabitat variables were recorded.

\section{Amphibian availability}

To evaluate a possible relationship between snake abundance and prey availability, we measured amphibian abundance in each habitat type. Amphibian surveys were conducted in the same area and following the same methodology as snake surveys. From January 2015 to September 2016, we counted the abundance of amphibians but did not record species identity. From October 2016 to August 2017, we also recorded species identity, using this information to assess which potential prey species were most abundant. Many amphibians are a common prey type for juvenile $B$. asper (Sasa et al., 2009), and some larger species for adults (Wasko \& Sasa, 2010). Adults largely specialise on small mammals, but mammal sampling was unfortunately not possible during the study.

\section{Data analyses}

We determined whether mean body length differed between males and females using a Mann-Whitney $U$ test. We assessed whether the population differed in proportions of a) juveniles vs. adults, b) overall males vs. females, and c) males vs. females within each age class using Chi-Square tests. We compared the number of snakes observed performing each recorded behaviour (resting, ambushing, or moving) during day vs. night observations and between habitat types.

We determined whether macrohabitat use differed from that predicted by random availability using a likelihood-ratio test. We then addressed snakes' relative use of each habitat using Manly selection ratios, calculated by the proportional use of a habitat divided by the proportional availability of that habitat (Manly et al., 2002). Selection ratios $>1$ indicate habitats with greater use relative to their availability; ratios $<1$ indicate habitats with lesser use. We also compared the number of individuals in each habitat type between wet and dry seasons and between juvenile and adult snakes using Pearson Chi-Square tests, in order to determine if macrohabitat use differed between seasons and age classes.

Microhabitat use was determined by comparing the values of microhabitat variables from actual snake locations with those from random points using MANOVA, with a difference between groups considered an indicator of active selection. Post-hoc Discriminant Function Analysis was used to determine which microhabitat variables contributed most to the difference between snake locations and random points, as it gives a coefficient of contribution for each variable. We similarly used MANOVA to compare microhabitats used by snakes for different activities, between seasons, and between age classes. Data from males and females were pooled for these analyses because microhabitat use does not seem to differ between sexes (Wasko \& Sasa, 2009; Wasko \& Sasa, 2010).

To evaluate the possible relationship between amphibian and snake abundances we used a Poisson regression model, with amphibian abundance as a continuous predictor variable. Juvenile and adult snakes were analysed separately. The coefficients produced by this model (positive, negative, or zero) indicate the directionality of the relationship between snake and amphibian abundance (positive, negative, or no relationship, respectively; Quinn \& Keough, 2002). To estimate the magnitude of such a relationship, we used incidence rates ratios, which indicate the percent change in the incident rate of the dependent variable for every unit increase/decrease in the predictor variable. A deviance goodness of fit test assessed the overall fit of the model to our data.

Mann Whitney $U$ tests were conducted in STATISTICA 8.0 (Weiß, 2007). All other analyses were conducted using program R 3.5.0 (R Core Team, 2018). For all tests, $\alpha=0.05$.

\section{RESULTS}

\section{Age structure and $B$. asper behaviours}

A total of 55 individual $B$. asper were captured during the study, with five recaptures. Across all age classes, females had a mean total length of $95.16 \pm 45.01 \mathrm{~cm}$ (range 31.50 $-174 \mathrm{~cm}$ ) and males $53.20 \pm 26.79 \mathrm{~cm}$ (range $29-136$ $\mathrm{cm}$; Fig. 2). Females were significantly larger than males

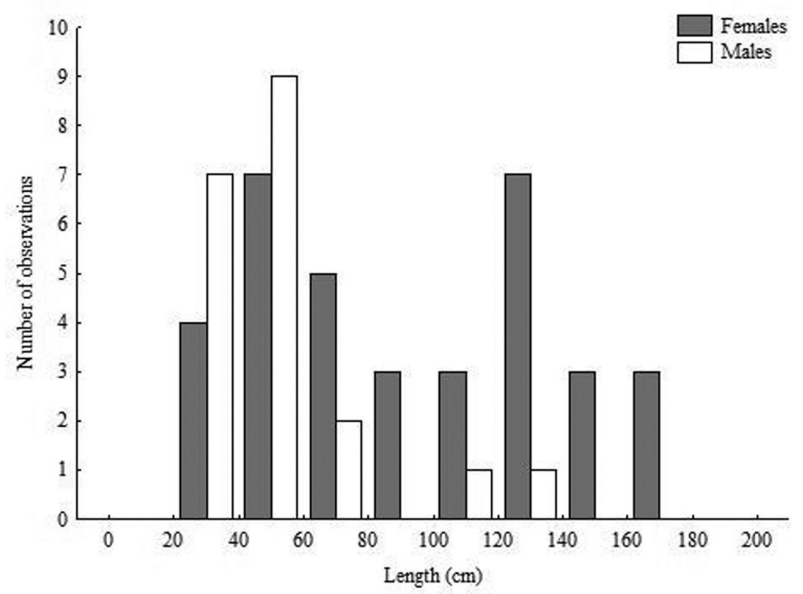

Figure 2. Size classes of $B$. asper males and females encountered at Quebrada Gonzalez sector of Braulio Carrillo National Park, Costa Rica.

$(U=158.50 ; p=0.0008)$, conforming to the expected size dimorphism of B. asper (Savage, 2002).

Thirty-nine individuals were juveniles $(70.90 \%$ of captures) and 16 were adults (29.10\%); this age class distribution was significantly non-random $\left(\chi^{2}=9.62 ; p\right.$ $=0.002)$. Thirty-five snakes were female $(63.63 \%)$ and 20 were male (36.36\%), a 1.75:1 female-male ratio. The overall sex-ratio across all age classes was significantly non-random $\left(\chi^{2}=4.09 ; p=0.043\right)$. Within age classes, sex ratio did not differ significantly in juveniles $\left(\chi^{2}=0.23\right.$; 
$p=0.631)$, but more adults were female $\left(\chi^{2}=9 ; p=\right.$ $0.002)$.

Snakes demonstrated significantly different behavioural patterns during the day and at night $\left(\chi^{2}=\right.$ 125.14; $p<0.0001)$. During the day, snakes were most often observed resting and inactive ( $73 \%$ of observations) and were never seen moving, while at night snakes were more often ambushing (61\% of observations) or moving (39\% of observations), and no snake was observed resting. Behaviours also differed significantly between habitat types $\left(\chi^{2}=12.85 ; p=0.002\right)$. In natural areas (Early succession, Late succession, Mature forest) snakes were more often observed ambushing, while in disturbed areas (Human infrastructure) they were most often seen moving (Fig. 3).

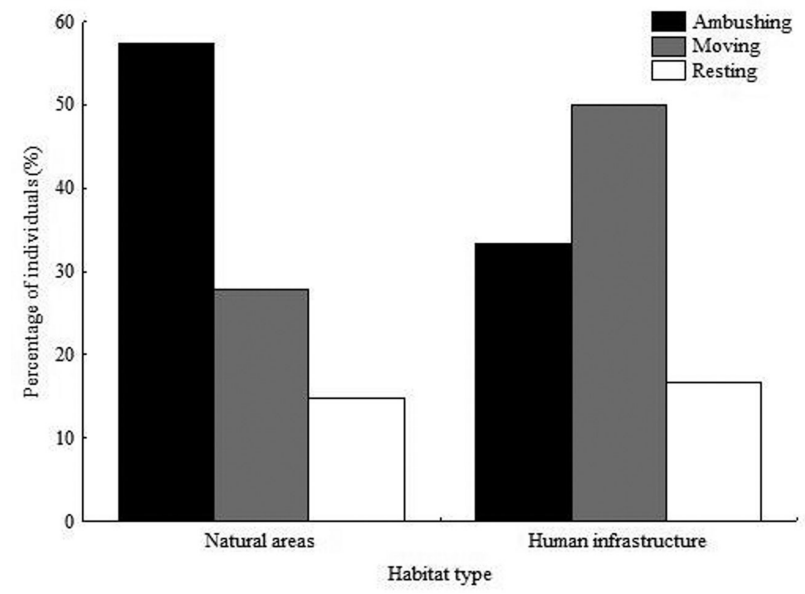

Figure 3. Percentage of $B$. asper individuals observed performing each recorded behaviour between natural and human-disturbed areas at Quebrada González sector, Braulio Carrillo National Park, Costa Rica. Data are pooled from both day and night observations.

\section{Habitat use}

Macrohabitat use by snakes was significantly non-random, indicating active selection $\left(G^{2}=52.77 ; p<0.0001\right)$ (Fig. 4). Early succession had selection ratios higher than 1 , indicating a higher use of this habitat relative to its availability, while Mature forest, Late succession and Human infrastructure were lesser used relative to availability (Table 3). Of all 60 snake encounters in both wet and dry seasons, the proportion actually found in

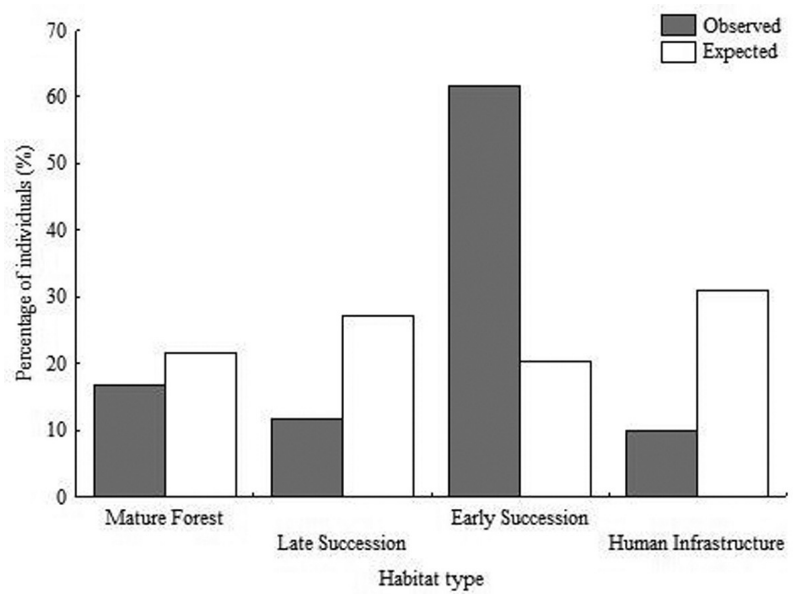

Figure 4. Percentage of $B$. asper individuals observed in each habitat type and percentage expected in each habitat type according to its availability at Quebrada González sector, Braulio Carrillo National Park, Costa Rica.

each macrohabitat type and the proportion predicted by availability of that habitat are presented in Table 3 . Macrohabitat use did not differ between seasons $\left(\chi^{2}=\right.$ 7.48; $p=0.06)$ or between age classes $\left(\chi^{2}=6.15 ; p=0.10\right)$.

Across all natural macrohabitat types, nearly all snakes (98.30\%) were found on soil/leaf litter. Only one individual was found on any other substrate, the branch of a tree at a height of $150 \mathrm{~cm}$. In Human infrastructure, all individuals were observed on pavement, except for one individual resting below fallen logs next to a building. All snakes encountered here were always near (12.50 \pm 5.60 $\mathrm{m}$ ) the edge of the forest or buildings, never being found completely in the open.

Snakes used significantly different microhabitat for the observed behaviours (Wilks' $\lambda=0.58 ; F_{10,100}=3.15 ; p$ $=0.001)$. Snakes resting were typically in more concealed areas with higher ground cover and close to fallen logs or trees, while snakes moving and ambushing were in more open areas with less ground cover, closer to bodies of water, and farther from fallen logs. However microhabitat use did not differ between age classes (Wilks' $\lambda=0.89 ; F_{5,51}$ $=1.28 ; p=0.29$ ) or between seasons (Wilks' $\lambda=0.90 ; F_{5,51}^{5,51}=$ $1.15 ; p=0.35)$. Data from both age classes and both seasons were therefore pooled for MANOVA analysis, which found overall microhabitat used by snakes differed significantly from that at random unused points (Wilks' $\lambda=0.47 ; F_{15,304}=$

Table 3. Proportional availability, proportional use by snakes and Manly's selection ratios for each habitat type on Quebrada González sector, Braulio Carrillo National Park, Costa Rica. Data is given for both wet and dry seasons, and pooled from both seasons. Selection ratios $>1$ indicate greater use of that habitat relative to its availability; ratios $<1$ indicate lesser use (Manly et al., 2002).

\begin{tabular}{|c|c|c|c|c|c|c|c|}
\hline \multirow{2}{*}{ Habitat type } & \multirow{2}{*}{$\%$ Available } & \multicolumn{3}{|c|}{$\%$ Used } & \multicolumn{3}{|c|}{ Selection Ratio } \\
\hline & & Wet season & Dry season & Overall & Wet season & Dry season & Overall \\
\hline Mature Forest & 0.22 & 0.19 & 0.14 & 0.17 & 0.86 & 0.64 & 0.77 \\
\hline Early Succession & 0.20 & 0.56 & 0.68 & 0.62 & 2.80 & 3.40 & 3.10 \\
\hline Late Succession & 0.27 & 0.06 & 0.18 & 0.12 & 0.22 & 0.67 & 0.44 \\
\hline Human Infrastructure & 0.31 & 0.19 & 0.00 & 0.10 & 0.61 & 0.00 & 0.32 \\
\hline
\end{tabular}


6.40; $\mathrm{p}<0.0001$ ). Discriminant Function Analysis revealed that percent structural ground cover, distance to nearest permanent water body, and distance to nearest fallen log contributed the most to this difference (Table 4).

Table 4. Microhabitat variables coefficients from Discriminant Function Analysis used to differentiate random points from those actually used by snakes at the Quebrada Gonzalez sector, Braulio Carrillo National Park, Costa Rica. Variables marked with an asterisk $(*)$ were significant at $\mathrm{P}<$ 0.05. DF = Discriminant function.

\begin{tabular}{lccc}
\hline Variable & DF1 & DF2 & DF3 \\
\hline $\begin{array}{l}\text { Ground cover } \\
\begin{array}{l}\text { Distance to nearest } \\
\text { permanent water body }\end{array}\end{array}$ & $0.92^{*}$ & -0.10 & -0.15 \\
$\begin{array}{l}\text { Distances to nearest } \\
\text { fallen log }\end{array}$ & $-0.39^{*}$ & $0.64^{*}$ & $0.60^{*}$ \\
$\begin{array}{l}\text { Distance to nearest tree } \\
\text { Eigenvalues }\end{array}$ & 0.14 & $-0.72^{*}$ & $0.68^{*}$ \\
Cumulative Proportion & 0.94 & 0.06 & 0.00 \\
\hline
\end{tabular}

\section{Amphibian availability}

A Poisson regression revealed a positive significant relationship between amphibian and juvenile snake abundance $(p=0.0002$, coefficient estimate $=0.07$, incidence rate ratio $=1.07$ ), indicating an approximately $7 \%$ increase in snake abundance for every unit increase in amphibian abundance. Adult snake abundance was not significantly associated with amphibian abundance $(p=0.18)$.

We identified 18 species of amphibians, of which at least six represent potential prey of $B$. asper (Solórzano, 2004; Sasa et al., 2009): the frogs Craugastor fitzingeri, Lithobates warszewitschii, L. vaillanti, Rhinella horribilis, Smilisca phaeota and S. sordida. Incilius melanochlorus and $L$. warszewitschii were the most abundant species, representing $70 \%$ of amphibian captures. We are unaware of reports of $B$. asper predating the toad species I. melanochlorus, however they are known feed on the similar toad $R$. horribilis.

Amphibian distributions along the Quebrada González sector was similar to snake distributions. Amphibians were more abundant in Early succession and Mature forest, and less abundant in Late succession and in Human infrastructure. Of 442 encounters, $44.8 \%$ were in Early succession, $33.03 \%$ in Mature forest, 17.4 $\%$ in Late succession, and $4.8 \%$ in Human infrastructure.

\section{DISCUSSION}

\section{Population structure}

The Fer-de-Lance population comprised a high proportion of juveniles and relatively few adults. $B$. asper has a high fecundity (up to 80 offspring per clutch) and annual or biennial reproduction (Solórzano \& Cerdas, 1989), so the large number of juveniles encountered is not surprising, even considering the greater difficulty of visually locating smaller snakes. While the species has a high survivorship in captivity (Sasa et al., 2009) and food resources such as rodents and amphibians are abundant at the study site (Ramírez-Arce, pers. obs.), greater mortality in the wild could explain the lower encounter rate of adults.

The population also demonstrated differences in sex ratio that varied with age class, with males and females encountered equally as juveniles, but the majority of adults being females. Litters are not known to be biased in sex ratio and both sexes have similar cryptic colouration, foraging behaviour, and home ranges (Wasko \& Sasa, 2010). The observed sex distribution may therefore be due to increased male mortality with ontogeny, as males tend to be smaller and may periodically demonstrate greater movement rates in search of females, which could consequently lead to a higher predation rate (Savage, 2002; Wasko \& Sasa, 2009). Males' smaller body size may also contribute to a lower detectability in visual surveys. Sex-ratio data may also be biased since the hemipenes-eversion technique can sometimes produces misidentification of large and heavy-bodied snakes (McDiarmid et al., 2012).

Lira-da-Silva (2009) reports the same pattern of a population becoming increasingly female-dominated with increasing age/size in the ecologically-similar $B$. leucurus, as a result of higher mortality rate among males. Sasa (2009) reported a population sample from agricultural regions of Pacific Costa Rica that was dominated by adult females rather than juveniles, but populations from other regions showed no bias in age or sex ratio. Thus, $B$. asper population structure may vary regionally depending on any number of ecological and anthropogenic factors (Seigel et al., 1987) or data may be biased by survey methodology and differential detectability of sex and age class (Solórzano, 2004; Morrison et al., 2006).

\section{Habitat use, behaviour, and prey association}

Bothrops asper were observed in all surveyed areas, with a higher proportion in Early succession. This habitat is characterised by dense herbaceous plants, shrubs, and small-diameter trees and a lower basal area typical of secondary forests, as opposed to the more open structure of primary forest seen in Mature forest (Guariguata et al., 1997; Guariguata \& Ostertag, 2001; Morales-Salazar et al., 2012). Snakes in this study were found principally using understory vegetation like shrubs, herbs, and small palms for shelter, and so may utilise the abundant lowlying plant cover of Early succession forest for protection and concealment (Blouin-Demers \& Weatherhead, 2001). Alternatively, a higher abundance of amphibians were observed in Early succession compare to the other habitat types, so snakes may preferentially use these areas due to higher prey availability. This could also explain why we saw more snakes resting and ambushing in natural areas than in Human infrastructure, since natural areas provide higher prey availability and shelter. Although snakes were found in human-disturbed areas less than expected, they were seen ambushing and resting on some occasions. This may be explained by $B$. 
asper's overall behavioural plasticity, as it demonstrates a willingness to at least enter a wide variety of habitats with varying structural complexity, including forests, pastures, agricultural fields, and rural human settlements (Sasa et al., 2009). This seems to be a property of Bothrops in general, as other species in the genus such as $B$. atrox, $B$. leucurus, and $B$. pubescens demonstrate similar habits (Oliveira, 2001; Hartmann et al., 2005; Lira-daSilva, 2009). However the majority of snakes observed in Human infrastructure were actively moving, and so may be interpreted as "crossing" these areas rather than actively "using" them, moving through a non-preferred habitat to one with higher structural cover and prey availability (Wasko \& Sasa, 2010).

Nearly all individuals were located on the ground, which concurs with other studies and is unsurprising since adult $B$. asper are terrestrial ambush-foragers, fairly heavy-bodied, and lack the gap-bridging ability of arboreal snakes (Martins et al., 2001; Sasa et al., 2009). However juveniles are frequently reported using shrubs or fallen trees, and even adults have occasionally been observed using branches of trees at heights of more than $2 \mathrm{~m}$ (Sasa et al., 2009; Vega-Coto et al., 2015), as in this study.

Bothrops asper at the study site preferentially utilised areas with high plant cover and/or fallen logs while resting during the day, and ambushed and moved in areas with reduced structural cover at night. This pattern is similar to that observed for the nearby $B$. asper population at La Selva Biological Station and for the related $B$. atrox and B. neuwiedi (Oliveira, 2001; Valdujo et al., 2002), as well as for the tropical rattlesnake Crotalus durissus in Brazil (Tozetti \& Martins, 2008). Such habits are typically explained as snakes utilising vegetation as refuge while inactive during the day, then selecting open areas for nocturnal ambush foraging, where they can more easily detect prey (Seigel et al., 1987). This may also explain why most snakes observed during the study were seen ambushing and moving, since $B$. asper have been documented as spending most of their time resting in concealment, conditions in which visual detection is difficult or impossible (Wasko \& Sasa, 2009, 2010).

Snakes at the study site actively selected for proximity to bodies of water when they were ambushing or moving. Since juvenile snake abundance and distribution associated positively with amphibian abundance and distribution in our study, we can infer $B$. asper's selection of water may be explained by greater availability of amphibian prey. Juvenile $B$. asper feed heavily on amphibians (Martins et al., 2002), including the most frequently-encountered species at the study site. A similar pattern was described by Wasko \& Sasa (2010) and Wasko \& Sasa (2012) where B. asper demonstrated a strong association with water in order to feed on large amphibians, as a result of a low availability of mammalian prey at that time. Proximity to bodies of water may also be explained as snakes using water itself as a resource (such as for drinking), snakes using rivers and streams to move from one ambush site to another, or snakes searching for others types of prey like small mammals.
Similar water-association is seen among other Bothrops species (Oliveira, 2001; Valdujo et al., 2002; Nogueira et al., 2003).

Unlike juveniles, adult snakes were not associated with amphibian abundance. Bothrops asper shows an ontogenetic change in diet, with a shift towards smallmammals specialisation as an adult (Martins et al., 2002). We were unable to methodically sample small mammals during this study, but numerous individuals were observed opportunistically. We confirmed the presence of a number of rodent species including Heteromys desmarestianus, Melanomys chrysomelas, Mus musculus, Nyctomys sumichrasti, Proechimys semispinosus and Rheomys sp. Adult $B$. asper responded strongly to an experimental availability of rodent prey at the La Selva Biological Station in Costa Rica (Wasko \& Sasa, 2012), so further research is needed to evaluate the relationship of $B$. asper to mammalian food resources under natural conditions.

\section{Snakebite management}

Bothrops asper is a highly-venomous species responsible for the highest number of snakebites to humans in Central and northern South America, and is thus of great medical significance (Otero-Patiño, 2009). Studies such as this provide information important to understanding $B$. asper distributions and behaviour, which is critical to managing snakebite risk for people working or residing in natural, rural, or agricultural areas where encounters with B. asper is most likely (Hansson et al., 2013). For example, this information may allow park rangers to provide recommendations that help visitors to protected natural areas avoid snakebite accidents. Institutions like Costa Rica's Ministerio de Ambiente y Energía also utilise such information in educational outreach programs intended to minimise snakebite risk in rural areas. Additional studies of venomous snakes under natural conditions further our understanding of the factors explaining presence, abundance, and activity of these animals, as well as to manage the risk they can present to humans.

\section{ACKNOWLEDGEMENTS}

The authors thank Quebrada González sector officials Fabio Valerio Benavides, Roger Gómez Loría, Carlos Alfaro Trejos, Maritza Muñoz Sibaja and Pedro Ezeta Saliscetti for all the help and use of facilities they provided during the study period. We thank Jorge Hernández Benavides from Ministerio de Ambiente y Energía de Costa Rica for granting permission to conduct this research. We thank Alejandro Durán Apuy, Alexander Gómez Lépiz and Hector Zumbado Ulate for providing equipment, assisting with technical and statistical issues and for guidance in completing the thesis project on which this manuscript is based. Finally, we thank Alejandra Bolaños Hidalgo, Andrés Astorga Agüero, and Sebastián Jiménez Thuel for contributing to survey efforts. 


\section{REFERENCES}

ATLAS. (2014). Instituto Tecnológico Costarricense. Cartago, Costa Rica.

Blouin-Demers, G. \& Weatherhead, P.J. (2001). Habitat use by black rat snakes (Elaphe obsoleta obsoleta) in fragmented forests. Ecology 82, 2882-2896.

Bolaños, R. (1972). Toxicity of Costa Rican snake venoms for the white mouse. American Journal of Tropical Medicine and Hygiene 21, 360-363.

Brito, J.C. (2003). Seasonal variation in movements, home range, and habitat use by male Vipera latastei in northern Portugal. Journal of Herpetology 37, 155-160.

Charland, M.B. \& Gregory, P.T. (1995). Movements and habitat use in gravid and nongravid female garter snakes (Colubridae: Thamnophis). Journal of Zoology 236, 543-561.

Cisneros-Heredia, D.F. \& Touzet, J.M. (2004). Distribution and conservation status of Bothrops asper (Garman, 1884) in Ecuador. Herpetozoa 17, 135-141.

Guariguata, M.R., Chazdon, R.L., Denslow, J.S., Dupuy, J.M. \& Anderson, L. (1997). Structure and floristics of secondary and old-growth forest stands in lowland Costa Rica. Plant Ecology 132, 107-120.

Guariguata, M.R. \& Ostertag, R. (2001). Neotropical secondary forest succession: changes in structural and functional characteristics. Forest Ecology and Management 148, 185206.

Guyer, C. \& Donnelly, M.A. (1990). Length-mass relationships among an assemblage of tropical snakes in Costa Rica. Journal of Tropical Ecology 6, 65-76.

Hansson, E., Sasa, M., Mattisson, K., Robles, A. \& Gutiérrez, J.M. (2013). Using geographical information systems to identify populations in need of improved accessibility to antivenom treatment for snakebite envenoming in Costa Rica. PLOS Neglected Tropical Diseases 7, 1-13.

Hartmann, M.T., Hartmann, P.A., Cechin, S.Z. \& Martins, M. (2005). Feeding habits and habitat use in Bothrops pubescens (Viperidae, Crotalinae) from southern Brazil. Journal of Herpetology 39, 664-667.

Janzen, D.H. (1980). Historia natural de Costa Rica. Editorial Universidad de Costa Rica, San José, Costa Rica.

Lira-da-Silva, R.M. (2009). Bothrops leucurus Wagler, 1824 (Serpentes; Viperidae): Natural history, venom and envenomation. Gazeta Médica da Bahia 79, 56-65.

Lücking, R. (1999). Ecology of foliicolous lichens at the "Botarrama" trail (Costa Rica), a Neotropical rain forest. I. Species composition and its ecogeographical implications. Biotropica 31, 553-564.

Manly, B.F.J., McDonald, L.L., Thomas, D.L., McDonald, T.L. \& Erickson, W.P. (2002). Resource selection by animals: Statistical design and analysis for field studies. Kluwer Academic, Dordrecht, Netherlands.

Martins, M., Araujo, M.S., Sawaya, R.J. \& Nunes, R. (2001). Diversity and evolution of macrohabitat use, body size and morphology in a monophyletic group of Neotropical pitvipers (Bothrops). Journal of Zoology 254, 529-538.

Martins, M., Marques, O.A.V. \& Sazima, I. (2002). Ecological and phylogenetic correlates of feeding habits in Neotropical pitvipers of the genus Bothrops. In: Schuett, G.W., Höggren, M., Douglas, M.E., Greene, H.W. (Eds.), Biology of the Vipers. Eagle Mountain Publishing, Eagle Mountain, pp. 307-328.
McDiarmid, R.W., Foster, M.S., Guyer, C., Gibbons, J.W. \& Chernoff, N. (2012). Reptile Biodiversity: Standard Methods for Inventory and Monitoring. University of California Press, California, United States of America.

Morales-Salazar, M., Vílchez-Alvarado, B., Chazdon, R.L., Ortega-Gutiérrez, M., Ortiz-Malavassi, E. \& GuevaraBonilla, M. (2012). Diversidad y estructura horizontal en los bosques tropicales del Corredor Biológico de Osa, Costa Rica. Revista Forestal Mesoamericana Kurú 9, 19-28.

Morrison, M.L, Marcot, B.G. \& Mannan, R.W. (2006). WildlifeHabitat Relationships: Concepts and Applications. Island Press, Washington, United States of America.

Nogueira, C., Sawaya, R.J. \& Martins, M. (2003). Ecology of the pitviper, Bothrops moojeni, in the Brazilian cerrado. Journal of Herpetology 37, 653-659.

Oliveira, M.E. (2001). When and where to find a pitviper: activity patterns and habitat use of the lancehead, Bothrops atrox, in Central Amazonia, Brazil. Herpetological Natural History 8, 101-110.

Otero-Patiño, R. (2009). Epidemiological, clinical and therapeutic aspects of Bothrops asper bites. Toxicon 54, 998-1011.

Oviedo-Pérez, P.E. \& Fournier-Gutiérrez, L. (2008). Caracterización de la avifauna del sector Quebrada González, Parque Nacional Braulio Carrillo, Costa Rica. Brenesia 69, 25-33.

Pearson, D., Shine, R. \& Williams, A. (2005). Spatial ecology of a threatened python (Morelia spilota imbricata) and the effects of anthropogenic habitat change. Austral Ecology 30, 261-274.

QGIS Development Team. (2016). QGIS Geographic Information System. Open Source Geospatial Foundation Project. http://qgis.osgeo.org.

Quinn, G.P. \& Keough, M.J. (2002). Experimental Design and Data Analysis for Biologist. Cambridge University Press, New York, United States of America.

R Core Team. (2018). R: A language and environment for statistical computing. R Foundation for Statistical Computing, Vienna, Austria. http://www.R-project.org/.

Ramírez-Arce, D.G., Vega-Coto, J., Zúñiga-Ortiz, A., ArtaviaLeón, A., Baaijen, W. \& Wasko, D.K. (2019). Snake diversity (Squamata: Serpentes) in Quebrada González Sector of Braulio Carrillo National Park, Costa Rica. Herpetological Conservation and Biology 14, 212-222.

Sasa, M., Wasko, D.K. \& Lamar, W.W. (2009). Natural history of the terciopelo Bothrops asper (Serpentes: Viperidae) in Costa Rica. Toxicon 54, 904-922.

Savage, J. (2002). The Amphibians and Reptiles of Costa Rica. The University of Chicago Press, Chicago, United States of America.

Schelhas, J. \& Sánchez-Azofeifa, G.A. (2006). Post-frontier forest change adjacent to Braulio Carrillo National Park, Costa Rica. Human Ecology 34, 407-431.

Seigel, R.A., Collins, J.T. \& Novak, S.S. (1987). Snakes: Ecology and Evolutionary Biology. McGraw-Hill, New York, United States of America.

Solórzano, A. \& Cerdas, L. (1989). Reproductive Biology and Distribution of the Terciopelo, Bothrops asper Garman (Serpentes: Viperidae), in Costa Rica. Herpetologica 45, 444-450.

Solórzano, A. (2004). Serpientes de Costa Rica: Distribución, Taxonomía e Historia Natural. INBio, Heredia, Costa Rica.

Tenorio, R. (1993). Parque Nacional Braulio Carrillo, un viaje a 
la Biodiversidad. Ministerio del Ambiente y Energía, Sistema Nacional de Áreas de Conservación, Área de Conservación Cordillera Volcánica Central, Costa Rica.

Tozetti, A.M. \& Martins, M. (2008). Habitat use by the SouthAmerican rattlesnake (Crotalus durissus) in south-eastern Brazil. Journal of Natural History 42, 1435-1444.

Valdujo, P.H., Nogueira, C. \& Martins, M. (2002). Ecology of Bothrops neuwiedi pauloensis (Serpentes: Viperidae: Crotalinae) in the Brazilian Cerrado. Journal of Herpetology 36, 169-176.

Vásquez-Acosta, D. (2009). Historia de vida de cinco especies de Baétidos (Ephemeroptera: Baetidae) en la Quebrada González, Parque Nacional Braulio Carrillo. (Licenciatura thesis). Universidad de Costa Rica, San José, Costa Rica.

Vega-Coto, J., Ramírez-Arce, D., Baaijen, W., Artavia-León, A. \& Zúñiga-Ortiz, A. (2015). Bothrops asper. Arboreal behavior. Mesoamerican Herpetology 2, 199-201.
Wasko, D.K. \& Sasa, M. (2009). Activity Patterns of a Neotropical Ambush Predator: Spatial Ecology of the Fer-de-lance (Bothrops asper, Serpentes: Viperidae) in Costa Rica. Biotropica 41, 241-249.

Wasko, D.K. \& Sasa, M. (2010). Habitat selection of the terciopelo (Serpentes: Viperidae: Bothrops asper) in a lowland rainforest in Costa Rica. Herpetologica 66, 148158.

Wasko, D.K. \& Sasa, M. (2012). Food resources influence spatial ecology, habitat selection, and foraging behavior in an ambush-hunting snake (Viperidae: Bothrops asper): an experimental study. Zoology 115, 179-187.

Weiß, C.H. (2007). StatSoft Inc, Tulsa, OK.: STATISTICA, Version 8. AStA. Advances in Statistical Analysis 91(3), 339-341. doi:10.1007/s10182-007-0038-x.

Accepted: 24 October 2020

Please note that the Supplementary Materials are available via the Herpetological Journal website: https://thebhs.org/publications/the-herpetological-journal/volume-31-number1-january-2021 